\title{
Serial position effects in social transmission of food preference
}

\author{
C. EDITH JUÁREZ-MALDONADO, GUADALUPE ORTEGA-SAAVEDRA, \\ FRANCISCO HUICHAN-OLIVARES, JOSÉ GÓMEZ-ROMERO, \\ SARA E. CRUZ-MORALES, and J. C. PEDRO ARRIAGA-RAMÍREZ \\ National Autonomous University of Mexico, Tlalnepantla, Mexico
}

\begin{abstract}
The serial position effect in Long-Evans rats was evaluated in two experiments. In Experiment 1, the effect in a group for which an interstimulus interval (ISI) was introduced between items in a list of demonstrators was compared with that in a group without an ISI. With an ISI, a recency effect was produced. In Experiment 2, a serial position effect group was compared with four groups in which either the distinctiveness or the context of the middle item was changed, relative to the items on either side of it. A von Restorff effect was produced when a rat from a different strain was used as a demonstrator in Position 2. The results for Experiment 1 are discussed in relation to interstimulus effects in monkeys and those for Experiment 2 with respect to changes in the physical properties of middle items.
\end{abstract}

When a list of items is presented, the items at the beginning and end of the list are remembered better than the items in the middle of the list. This phenomenon is called the serial position effect, and the improved recall at the beginning and at the end of the list are termed primacy and recency effects, respectively.

Items in the middle of the list are not recalled as well as items at either end of the list (Atkinson \& Shiffrin, 1968). Primacy and recency effects have been found in several animal species (Bolhuis \& van Kampen, 1988; Crystal \& Shettleworth, 1994; DiMattia \& Kesner, 1984; Harper, Dalrymple-Alford, \& McLean, 1992; Harper, McLean, \& Dalrymple-Alford, 1993; Reed, 2000b; Reed, Chih-Ta, Aggleton, \& Rawlins, 1991; Wright, 1994). Serial position effects have been found in humans, monkeys, and pigeons (Santiago \& Wright, 1984; Wright, Santiago, Sands, Kendrick, \& Cook, 1985). With rats as subjects, primacy and recency effects have been found in spatial tasks (Bolhuis \& van Kampen, 1988; DiMattia \& Kesner, 1984; Harper et al., 1992; Harper et al., 1993; Reed et al., 1991) and in nonspatial tasks such as the flavor paradigm, in which Reed and his colleagues have studied the serial recall of flavored solutions (Reed, 2000a, 2000b; Reed, Croft, \& Yeomans, 1996). For example, following the presentation of five novel, flavored solutions, rats consumed more of the first and last items of the lists presented (Reed, 2000b). Reed interpreted this difference as a serial position effect and concluded that the relative novelty of the

This research was financed in part by PAPIIT IN301106-3, CONACYT (3665PH), and PAPCA $(2000,2003)$. The authors thank Bennett G. Galef, Jr., who read a draft of the manuscript. Correspondence concerning this article should be sent to J. C. P. Arriaga-Ramírez, UNAM Campus Iztacala, División de Investigación y Posgrado, Av. de los Barrios \#1, Tlalnepantla, Edo. Mex., CP 54090 Mexico (e-mail: jcpedro@servidor .unam.mx). flavors was not responsible for the effects observed. In that study, the main sources of information presented to the subjects were the tastes and smells of the flavored liquids in the list. In subsequent experiments, Reed (2000a) found that, as the interstimulus interval (ISI) was lengthened, the primacy effect was reduced, and an increased recency effect was produced. These effects are at variance with those produced in humans but are similar to those produced with monkeys as subjects (Cook, Wright, \& Sands, 1991). Cook et al. found that increasing the ISI reduced accuracy in monkeys and increased recency.

Although recall of items in the middle of the list is typically poor, recall of these items can be enhanced if an unusual or outstanding event occurs in the otherwise homogeneous series of items. This effect is termed the von Restorff effect (Reed et al., 1991; Reed \& Richards, 1996; von Restorff, 1933). These effects - the serial position effect and the von Restorff effect - have been studied in rats with a Y-maze (Reed et al., 1991). In that study, a change in illumination in the middle box produced an enhanced recall of the items in that box, a von Restorff effect. Reed and Richards, using an eight-arm radial maze, marked the entry to the third arm in a list of five by handling subjects or by adding a tone. They found fewer errors in later recall of this third arm and interpreted this result as a von Restorff-like effect. The nonspatial task used by Reed (2000a, 2000b) may be used to produce a von Restorff effect by changing the distinctiveness of the middle item.

In adult rats, a rat that has eaten flavored food will increase preference for that food in a naive rat with which it comes into contact (Galef \& Wigmore, 1983; PosadasAndrews \& Roper, 1983), a phenomenon that illustrates social transmission of food preferences and that may be used to study memory processes. For example, Galef and Durlach (1993) found absence of blocking (Kamin, 1969) in a study in which the conditioned stimulus properties 
of the flavor of food that demonstrators had eaten were evaluated. This absence of blocking demonstrates that rats are able to process at least two social stimuli in sequence without the first interfering with the second and is similar to that in Reed (2000a), in which it was reported that the effects produced in the flavor paradigm were not produced by a generalization decrement. One interesting issue, then, is whether rats are able to process olfactory cues in the same way that they process visual and spatial cues, as has been shown in the studies of Bolhuis and van Kampen (1988), DiMattia and Kesner (1984), Harper et al. (1992), and Harper et al. (1993). The studies relating to the flavor paradigm (Reed, 2000a, 2000b) suggest that they can.

On the basis of the studies reviewed above, the primary purpose of the present study was to test whether rats would show a serial position effect for a series of flavors, presented by a list of demonstrators that had each eaten a different-flavored food. The amount of flavored food consumed by observers may be used as an index of preference or, alternatively, as an index of recall of the flavors presented at different serial positions. A second objective was to assess whether the effect of lengthening the ISI between demonstrators would affect the effects produced and, if so, whether a recency effect would be produced. A third objective was to evaluate whether a change in the physical properties of the middle item, with regard to either the distinctiveness or the context, would produce a von Restorff effect.

\section{EXPERIMENT 1}

In this experiment, demonstrators that had eaten differentflavored foods were presented to naive observers to determine whether a serial position effect would be produced. This group was compared with one that experienced a longer ISI between each demonstrator presentation.

\section{Method}

Subjects. Thirty naive, female Long-Evans rats from the university vivarium were used as demonstrators and observers. The rats ranged in age from 40 to 70 days old and in free-feeding body weight from 205 to $287 \mathrm{~g}$. The rats were food deprived, except when having free access to chow (Harlan, Mexico City) for 20 min each day. The subjects were housed in individual steel boxes and had free access to water. The rats occupied a room that had a 12:12-h light:darkness cycle and in which the ambient temperature was kept between $21^{\circ}$ and $26^{\circ} \mathrm{C}$.

Apparatus and Materials. The subjects were housed individually in steel boxes (Armexa, Mexico City) that were $18 \mathrm{~cm}$ high, $18 \mathrm{~cm}$ wide, and $24 \mathrm{~cm}$ long. The demonstrators were fed in their home cages with powdered flavored chow. Food was mixed with one of three flavors: $1 \%$ cinnamon (McCormick, Mexico City), $2 \%$ cocoa (Hershey's, Mexico City), or $0.5 \%$ vanilla (Flor de Maria, Mexico City), all by weight. Demonstrations were performed in a Plexiglas demonstration box that was $26 \mathrm{~cm}$ wide, $15 \mathrm{~cm}$ high, and $36 \mathrm{~cm}$ long. For the preference test, flavored chow was presented in metal containers that were $2.4 \mathrm{~cm}$ high, $5 \mathrm{~cm}$ wide, and $7.5 \mathrm{~cm}$ long. The containers were wired to the rear wall of a Plexiglas test box that was $46 \mathrm{~cm}$ wide, $20 \mathrm{~cm}$ high, and $53 \mathrm{~cm}$ long and were separated by Plexiglas lids that were $1 \mathrm{~cm}$ wide, $1 \mathrm{~cm}$ high, and $15 \mathrm{~cm}$ long. The chamber and containers were cleaned after each observer had completed its 20-min test. An Ohaus balance, Model 310, with a 0.01-g resolution was used to weigh the amount of remaining food and to calculate the amount consumed by the subjects.

Procedure. After 7 days of a feeding regime of 20-min access to food per day, each of 24 rats was presented, sequentially, with 3 demonstrators, each of which had eaten, for $30 \mathrm{~min}$, one of three flavored foods. The food, powdered chow, was mixed with one of three flavors: $1 \%$ cinnamon, $2 \%$ cocoa, or $0.5 \%$ vanilla, before being given to the demonstrators. The demonstrators also were subjected to a feeding regime so that they would consume flavored food before the demonstrations took place. The order of demonstrator presentation was counterbalanced across observers. Each flavor of food was presented four times in each of the three positions in the list, both for demonstration and for testing. The naive observers interacted, individually and for periods of $15 \mathrm{~min}$, with each of the 3 demonstrators. The observers remained in the demonstration box, and the demonstrators were successively placed in the box for $15 \mathrm{~min}$. After demonstration, the observers were individually given a preference test in a Plexiglas test box in which three metal containers were wired to one side. The rats had access to $20 \mathrm{~g}$ of each of the three flavored foods, placed in the three separate containers. The position of the foods was balanced across subjects. Preference was measured for $20 \mathrm{~min}$. The amount consumed was considered as much a measure of preference as an index of recall. For 12 of the subjects, the serial position group, the demonstrators were presented, individually, one after the other, for periods of $15 \mathrm{~min}$ each. Immediately after the last demonstrator had been presented for $15 \mathrm{~min}$, a preference test was initiated. For the remaining 12 subjects, the ISI group, an ISI of 15 min was inserted after each of the demonstrators. During this interval, the observer remained alone in the demonstration box. In this group, the preference test was initiated $15 \mathrm{~min}$ after the third (i.e., the last) demonstrator had been withdrawn. This ISI was the only difference between the two groups.

\section{Results}

Figure 1 shows the mean percentage of flavored food consumed at each serial position $( \pm S E)$ for the two groups in this experiment. An examination of the figure revealed that a recency effect was evident in the ISI group. A mixed ANOVA, with group as a between-subjects factor and serial position as a within-subjects factor, revealed a nonsignificant effect of position $[F(2,44)=3.155, p=.052]$ and a significant interaction between serial position and group $[F(2,44)=7.694, p=.001]$. A test of within-subjects contrasts revealed a significant linear trend for serial position $[F(1,22)=8.204, p=.009]$ and a significant linear trend for the interaction of serial position with group $[F(1,22)=$ $18.948, p<.001]$. Pairwise comparisons between serial positions revealed a significant difference between Position 1 and Position 3 (Bonferroni adjustment, $p=.05$ ). In the ISI group, there was a significant difference between Position 1 and Position 2 and between Position 1 and Position $3(p=.05)$. Trend tests were conducted, first, on combined groups and, later, on individual groups, using an ANOVA test with group and serial position as factors. This test revealed a nonsignificant effect of group $(F<1)$, a significant effect of serial position $[F(2,66)=4.732, p=$ $.012]$, and a significant interaction of group and serial position $[F(2,66)=11.54, p<.001]$. Planned comparisons showed a significant global linear trend $[F(1,66)=8.44$, $p=.005]$ and a nonsignificant global quadratic trend $(p>$ $.05)$. Individual planned comparisons for trend showed a significant linear trend in the ISI group $[F(1,66)=26.81$, $p<.001]$. A repeated measures ANOVA of the percent- 


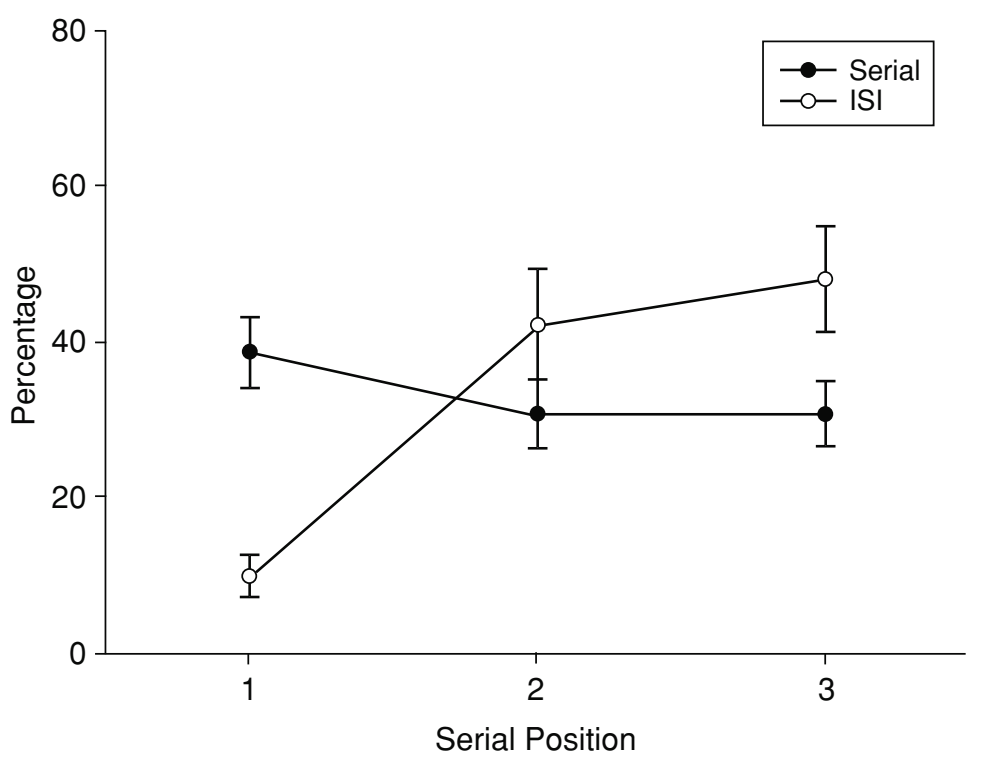

Figure 1. Mean percentage of flavored food consumed $( \pm S E)$ in each of the serial positions of the two groups in Experiment 1.

age of flavored food consumed, grouped by flavor, did not show a reliable difference in the amount of individual flavors consumed $(p>.05)$.

\section{Discussion}

In the ISI group, a recency effect was produced. The differences between Position 1 and Position 2 and between Position 1 and Position 3, combined with the significant linear trend, showed that the item in Position 3 was remembered better. This enhanced recall of the flavor in Position 3 is a recency effect. This result is similar to those obtained by Cook et al. (1991), who found that monkeys with ISIs of $0.08,1$, and $4 \mathrm{sec}$ showed an increased recency effect with longer ISIs, and to those obtained by Reed (2000a), who found also that rats with ISIs of 3.5, 10, and $60 \mathrm{sec}$ showed an increased recency effect when the ISI was $60 \mathrm{sec}$.

\section{EXPERIMENT 2}

In studies of list recall, a von Restorff effect (Reed et al., 1991; von Restorff, 1933) is obtained when the physical conditions of the element in the middle of the list are changed in such a way that it stands out, in comparison with the rest of the items in the list. The purpose of this experiment was to determine whether changing the physical conditions for the demonstrator's presentation in Position 2 would produce a von Restorff effect.

\section{Method}

Subjects. Forty-five naive, female Long-Evans rats were used as observers. The demonstrators consisted of 15 female and 3 male LongEvans rats, along with 3 female Wistar rats. The age range was as in Experiment 1 , and the free-feeding body weight range was $211-293 \mathrm{~g}$.

Apparatus and Materials. The apparatus and materials were identical to those used in Experiment 1.
Procedure. In this experiment, 3 demonstrators, each having eaten a different flavored food, were presented successively to each of 9 observers in each of five groups, in the demonstration box. The physical conditions of the item presented in Position 2 were varied across the different groups. In Group Wistar, a female Wistar rat was presented between 2 female Long-Evans demonstrators. In Group Female, a Long-Evans female rat was presented between 2 LongEvans male demonstrators. In Group Dark, all 3 demonstrators were Long-Evans females; however, the light in the experimental room was turned off during the presentation of Demonstrator 2. In Group Double, all 3 demonstrators were Long-Evans females; however, the demonstrator in Position 2 had the amount of flavor in its diet doubled. These four groups were compared with a serial position group, in which all the demonstrators were Long-Evans females but were presented with no outstanding quality associated with the item in Position 2. Immediately after each individual demonstration period had ended, the observers were given a 20 -min preference test, in which they had access to $20 \mathrm{~g}$ each of the flavored foods - cinnamon, cocoa, and vanilla - with position balanced in the test box. Each flavor was presented three times, in each of the three positions in the list, for both demonstration and testing.

\section{Results}

Figure 2 presents the mean percentage consumed for each position and for the five groups in Experiment 2. In Group Wistar, a von Restorff effect was produced, the second item having been better recalled. In Group Dark, a primacy effect was evident. A repeated measures ANOVA, with position as a within-subjects factor and group as a between-group factor, revealed a significant effect of serial position $[F(2,80)=3.793, p=.027]$. The interaction of group with position was nonsignificant $(p>.05)$. A within-subjects contrast was significant for a linear trend $[F(1,40)=6.335, p=.016]$. The interaction of position and group was nonsignificant $(p>.05)$. The main between-group effect was not significant $(p>.05)$. A simple contrast made to all the groups, with the serial po- 


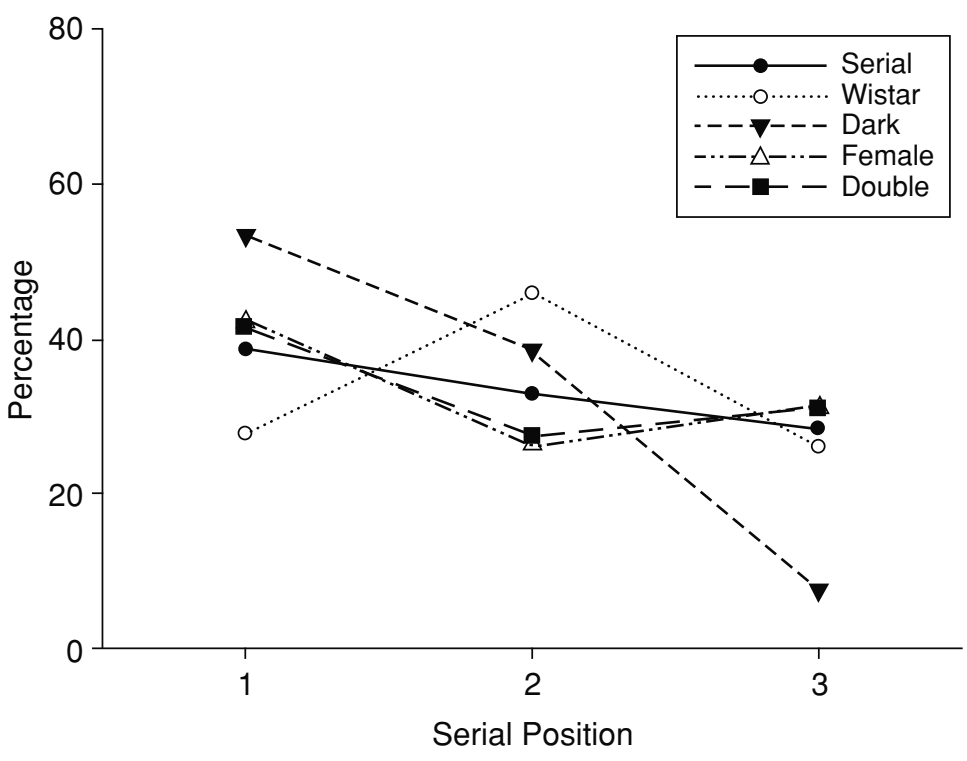

Figure 2. Mean percentage of flavored food consumed in each of the serial positions of the five groups in Experiment 2.

sition group as the reference category, did not reveal a significant difference $(p>.05)$.

Trend tests were conducted, first on combined groups and, later, on individual groups, using an ANOVA test, with group and serial position as factors. This test revealed a nonsignificant effect of group, a significant effect of serial position $[F(2,120)=5.689, p=.004]$, and a significant interaction between group and serial position $[F(8,120)=2.256, p=.027]$. Planned comparisons revealed a significant linear trend $[F(1,120)=11.253$, $p=.001]$ and a nonsignificant quadratic trend $(p>.05)$. Planned comparisons for individual groups revealed a significant linear trend for Group Dark $[F(1,120)=18.876$, $p<.001]$ and a significant quadratic trend for Group Wistar $[F(1,120)=4.327, p=.039]$.

A repeated measures ANOVA of the percentage of flavored food consumed, grouped by flavor, did not show a reliable difference in the amount of individual flavors consumed $(p>.05)$.

\section{Discussion}

Each of the second items in the four groups had a different outstanding quality. In Group Wistar, a von Restorff effect was evident. In Group Dark, primacy with respect to Positions 2 and 3 was increased. When the distinctiveness of the second item was changed, as in Groups Wistar, Female, and Double, a von Restorff effect was produced only in Group Wistar. Similar to the results of Neath (1993), who used context as a distracting task between items, we obtained an increased primacy effect in Group Dark.

\section{GENERAL DISCUSSION}

One question asked in these experiments was whether a serial position effect would be produced if a list of dem- onstrators was presented to naive observers. Experiment 1 showed that a recency effect was apparent in the ISI group when the presentation of demonstrators included observing a delay between items. Primacy effects have been found in nonhuman subjects performing nonspatial tasks (Reed, 2000a, 2000b; Reed et al., 1996). Recency effects also have been found in nonhuman subjects (Cook et al., 1991; Reed, 2000a).

The procedures that have shown primacy effects in animals have been questioned because the variance observed was lower than that expected on the basis of the binomial model, because the data were selected on the basis of response criteria, or because explicit observing responses to the first item in the list were required of subjects (Gaffan, 1992; Gaffan \& Gaffan, 1992). Reed $(1992,1994)$ has mentioned that the variance predicted by the binomial model may not be appropriate for these types of studies. Wright (1994) also has noted that primacy effects are not produced by list initiation responses. The subjects that showed recency effects in Experiment 1 were not selected by any criteria, no observing response was required of them, and their responses were not classified as correct or incorrect.

Another question asked in the experiments reported here was whether a von Restorff effect would be produced if the second item in a list of demonstrators presented a distinctive quality to the observers. As the results of Experiment 2 show, Group Wistar was the only group in which this effect was observed - that is, in which the second item was recalled better than both the first and the third items. It is possible that the latter items became agglutinated (Hunt, 1995). Hunt, in reviewing von Restorff's (1933) work, mentioned that nonisolated items may agglutinate in memory and that this will make the isolate different. This same interpretation may explain why a von Restorff effect was produced in Group Wistar. A rat 
from the Wistar strain became isolated, whereas the rats from the Long-Evans strain became agglutinated. The manipulation of the second item in the other groups did not produce the isolation effect. Performance in Group Dark showed that a change in illumination produced a primacy effect. This change in context may have increased the encoding process of the first item in the list presented to this group. A change in illumination for the second item of Group Dark did not isolate that item. The slight U-shaped serial position function observed in the female and double groups may represent a transitional effect between all primacy and all recency, dependent on certain values of the parameters manipulated in list elaboration, as Wright (1994) mentioned. The different items presented in the second position in Experiment 2 do not represent a continuous variable, and this may explain the differences in the effects observed. However, future experiments should explore several values of the items presented in Position 2 in this experiment.

Although we did not obtain a significant effect of primacy in Experiment 1, primacy was evident in Group Dark in Experiment 2. Recency was obtained only in the ISI group, a result similar to that found by Reed (2000a). It is possible that the ISI acted to isolate the last item and that this was recalled from short-term memory storage. It may be that in the different procedures used in other studies, in which only recency was obtained, an aspect of the procedure inadvertently separated the items and caused the last one to be retained in short-term memory storage and better recalled. This possibility is similar to the explanation offered by Kesner, Measom, Forsman, and Holbrook (1984). They found that an eight-item list was more difficult to learn than a four-item list. In the test phase, they found primacy with the eight-item list and recency with the four-item list. The authors interpreted their results as being a product of the degree of difficulty of the two lists, the eight-item list being more difficult to remember than the four-item list. Finally, it should be recognized that the question of how to shape task requirements in order to produce von Restorff effects must be explored in future experiments.

\section{REFERENCES}

Atkinson, R. C., \& Shiffrin, R. M. (1968). Human memory: A proposed system and its control processes. In K. W. Spence \& J. T. Spence (Eds.), The psychology of learning and motivation: Advances in research and theory (Vol. 2, pp. 89-195). New York: Academic Press.

Bolhuis, J. J., \& VAN KAMPEN, H. S. (1988). Serial position curves in spatial memory of rats: Primacy and recency effects. Quarterly Journal of Experimental Psychology, 40B, 135-149.

CoOK, R. G., Wright, A. A., \& SANDS, S. F. (1991). Interstimulus interval and viewing time effects in monkey list memory. Animal Learning \& Behavior, 19, 153-163.

Crystal, J. D., \& Shettleworth, S. J. (1994). Spatial list learning in black-capped chickadees. Animal Learning \& Behavior, 22, 77-83.

DiMattia, B. V., \& Kesner, R. P. (1984). Serial position curves in rats: Automatic versus effortful information processing. Journal of Experimental Psychology: Animal Behavior Processes, 10, 557-563.
Gaffan, E. A. (1992). Primacy, recency, and the variability of data in studies of animals' working memory. Animal Learning \& Behavior, 20, 240-252.

GAFFAN, E. A., \& GAFFAN, D. (1992). Less-than-expected variability in evidence for primacy and von Restorff effects in rats' nonspatial memory. Journal of Experimental Psychology: Animal Behavior Processes, 18, 298-301.

Galef, B. G., JR., \& DURLaCh, P. J. (1993). Absence of blocking, overshadowing, and latent inhibition in social enhancement of food preferences. Animal Learning \& Behavior, 21, 214-220.

GALEF, B. G., JR., \& WigMORE, S. W. (1983). Transfer of information concerning distant foods: A laboratory investigation of the "informationcentre" hypothesis. Animal Behaviour, 31, 748-758.

Harper, D. N., Dalrymple-Alford, J. C., \& McLean, A. P. (1992). Production of a serial position effect in rats using a 12-arm radial maze. Journal of Neuroscience Methods, 44, 197-207.

Harper, D. N., Mclean, A. P., \& Dalrymple-Alford, J. C. (1993). List item memory in rats: Effects of delay and delay task. Journal of Experimental Psychology: Animal Behavior Processes, 19, 307-316.

HunT, R. R. (1995). The subtlety of distinctiveness: What von Restorff really did. Psychonomic Bulletin \& Review, 2, 105-112.

Kamin, L. J. (1969). Predictability, surprise, attention, and conditioning. In B. A. Campbell \& R. M. Church (Eds.), Punishment and aversive behavior (pp. 279-296). New York: Appleton-Century-Crofts.

Kesner, R. P., Measom, M. O., Forsman, S. L., \& Holbrook, T. H. (1984). Serial-position curves in rats: Order memory for episodic spatial events. Animal Learning \& Behavior, 12, 378-382.

NeAth, I. (1993). Contextual and distinctive processes and the serial position function. Journal of Memory \& Language, 32, 820-840.

Posadas-AndRews, A., \& Roper, T. J. (1983). Social transmission of food-preferences in adult rats. Animal Behaviour, 31, 265-271.

REeD, P. (1992). Fewer doubts concerning rats' serial position performance: Reply to Gaffan and Gaffan (1992) and Rawlins, Deacon, Chih-Ta, and Aggleton (1992). Journal of Experimental Psychology: Animal Behavior Processes, 18, 305-307.

ReED, P. (1994). Less than expected variance in studies of serial position effects is not sufficient reason for caution. Animal Learning \& Behavior, 22, 224-230.

REED, P. (2000a). Rat's memory for serially presented flavors: Effects of interstimulus interval and generalization decrement. Animal Learning \& Behavior, 28, 136-146.

REED, P. (2000b). Relative novelty does not explain primacy effects in rats' memory for serially presented novel flavors. Learning \& Motivation, 31, 99-113.

Reed, P., Chin-Ta, T., Aggleton, J. P., \& Rawlins, J. N. P. (1991). Primacy, recency, and the von Restorff effect in rats' nonspatial recognition memory. Journal of Experimental Psychology: Animal Behavior Processes, 17, 36-44.

Reed, P., Croft, H., \& Yeomans, M. (1996). Rats' memory for serially presented novel flavours: Evidence for non-spatial primacy effects. Quarterly Journal of Experimental Psychology, 49B, 174-187.

REED, P., \& RichaRds, A. (1996). The von Restorff effect in rats. Journal of Comparative Psychology, 110, 193-198.

Santiago, H. C., \& Wright, A. A. (1984). Pigeon memory: Samel different concept learning, serial probe recognition acquisition, and probe delay effects on serial-position function. Journal of Experimental Psychology: Animal Behavior Processes, 10, 498-512.

vON RestorfF, H. (1933). Analyse von Vorgängen im Spurenfeld. I. Über die Wirkung von Bereichsbildungen im Spurenfeld [The effect of organization in perceptual fields]. Psychologische Forschung, 18, 299-342.

Wright, A. A. (1994). Primacy effects in animal memory and human nonverbal memory. Animal Learning \& Behavior, 22, 219-223.

Wright, A. A., Santiago, H. C., Sands, S. F., Kendrick, D. F., \& Cook, R. C. (1985). Memory processing of serial lists by pigeons, monkeys, and people. Science, 229, 287-289.

(Manuscript received May 12, 2005; revision accepted for publication March 30, 2006.) 